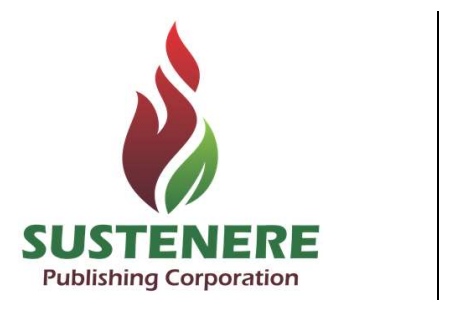

\section{REDES NA EDUCAÇÃO A DISTÂNCIA: UM ESTUDO SOBRE AS PRÁTICAS DO CURSO PILOTO DE ADMINISTRAÇÃO}

\section{RESUMO}

Esse estudo buscou identificar, na percepção dos coordenadores do curso de Administração a distância (piloto) do Sistema Universidade Aberta do Brasil (UAB), como se deu a interação/relacionamento entre as universidades participantes, quais as dificuldades enfrentadas pelos coordenadores e os possíveis benefícios que foram obtidos pelos egressos, permitindo identificar a repercussão dessa rede para a dinamização da Educação a Distância. Identificou-se que a rede formada entre as universidades foi eficiente na troca de conhecimento e experiências diversas o que garantiu o alcance dos objetivos da UAB, seja de capacitação dos alunos, seja na ampliação do acesso aos cursos superiores a distância.

PALAVRAS-CHAVES: Redes Interorganizacionais; Educação a Distância; Curso Piloto de Administração.

\section{NETWORKS IN ONLINE EDUCATION: A STUDY ABOUT THE PRACTICES OF MANAGEMENT PILOT COURSE}

\section{ABSTRACT}

This study sought to identify the perceptions of the course coordinators of Directors (pilot) away from the Open University System of Brazil (UAB), how was the interaction / relationship between the participating universities, including the difficulties faced by engineers and the possible benefits which were obtained by graduates, allowing to identify the impact that network for Advancing Distance Education. It was identified that the network formed between universities was efficient in the exchange of knowledge and diverse experiences which ensured the achievement of the goals of $U A B$, is the training of students, whether in expanding access to higher education distance courses.

KEYWORDS: Interorganization Networks; Online Education; Pilot Administration Course.
Revista Brasileira de

Administração Científica,

Aquidabã, v.6, n.1, Jan, Fev, Mar,

Abr, Mai, Jun 2014.

ISSN 2179-684X

SECTION: Articles

TOPIC: Recursos Humanos

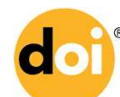

DOI: 10.6008/SPC2179-684X.2015.001.0004

Lilian Ferrugini

Instituto Federal de Educação de Minas Gerais, Brasil http://lattes.cnpq.br/0833634723805880

lilianufif@yahoo.com.br

Donizeti Leandro de Souza

Instituto Federal de Educação de Minas Gerais, Brasil http://lattes.cnpq.br/1574676998987257

souza.doni@yahoo.com.br

Raphael de Morais

Universidade Federal de Lavras, Brasil http://lattes.cnpq.br/2308872302689497

raphaelmoraisufla@gmail.com

Cleber Carvalho de Castro

Universidade Federal de Lavras, Brasil http://lattes.cnpq.br/8952886297485009 clebercastro@dae.ufla.br

Received: 24/10/2014

Approved: 14/10/2015

Reviewed anonymously in the process of blind peer.

Referencing this:

FERRUGINI, L.; SOUZA, D. L.; MORAIS, R.; CASTRO, C. C. Redes na educação a distância: um estudo sobre as práticas do curso piloto de Administração. Revista Brasileira de Administração Científica, Aquidabã, v.6, n.1, p.62-75, 2015. DOI:

http://dx.doi.org/10.6008/SPC2179$684 X .2015 .001 .0004$ 


\section{INTRODUÇÃO}

As transformações geradas pela globalização e as constantes mudanças ocorridas no mercado influenciam as organizações a moldarem suas estratégias de acordo com os ditames da sociedade e do mercado competitivo, surgindo à necessidade de buscar meios para manterem-se ativas perante aos obstáculos encontrados. Um desses meios se dá pela interação/relacionamento entre si, procurando meios de cooperação mútua, incentivos e mecanismos para aumento da produtividade, para geração e transferência de novos conhecimentos e criação de vantagens competitivas. Assim, a associação de organizações em redes, como um tipo específico de relações Inter organizacionais, é uma prática que vem se tornando comum entre os mais diversos tipos de organizações, em especial nesse estudo pelas Instituições Públicas de Ensino Superior (IPES). Infere-se que as organizações, ao buscarem algum tipo de interação, objetivam ampliar seu horizonte competitivo e criar condições para acessarem novos conhecimentos, os quais poderão conduzir a novas práticas de gestão e em ferramentas essenciais para melhoria de sua profissionalização (ESTIVALETE et al., 2012).

Outro fator que dinamiza a formação de uma rede entre Instituições de Ensino é o crescimento da demanda por educação superior no país. Ao se unirem em redes, as Instituições de Ensino Superior (IES) são capazes de melhorar seu desempenho e promover aumento do número de vagas ofertadas, algo ainda necessário no país, pois se sabe que o nível educacional tende a proporcionar aos indivíduos o desenvolvimento de conhecimentos, habilidades e competências para se manterem competitivos frente ao mercado global (FALK \& BLAYLOCK, 2010). Julga-se que a partir da união de competências em rede, as IES consigam oferecer acesso a educação em maior quantidade e melhor qualidade. Cada instituição com suas características peculiares, ao serem compartilhadas, melhoram o produto/serviço final repassado aos indivíduos. Buscando alcançar tais perspectivas é que foram instituídas algumas redes envolvendo Instituições Públicas de Ensino Superior (IPES) como o Sistema Universidade Aberta do Brasil (UAB), o qual tem sido a responsável pela dinamização da EaD. Assim, faz-se necessário verificar como e em que medida a formação dessa rede tem sido eficiente sobre a oferta de cursos superiores.

Nesse sentindo, o objetivo desse estudo é identificar, na percepção dos coordenadores do primeiro curso de Administração a distância (piloto) sob a égide do Sistema UAB, como se deu a interação/relacionamento entre as Universidades e qual a repercussão dessa rede para a dinamização da EAD, além de identificar algumas dificuldades enfrentadas pelos coordenadores e os possíveis benefícios que foram obtidos pelos egressos do curso. Justifica-se que esse estudo possa demonstrar como as relações entre IPES são capazes de proporcionar benefícios para as próprias Instituições e para a sociedade. Para tanto o artigo está organizado em cinco partes: nesta introdução, que incluiu o problema de pesquisa e o objetivo do estudo; no referencial teórico que abordará sobre as redes Inter organizacionais entre IPES, no conceito e abrangência da EaD 
no Brasil e do consórcio/Sistema UAB. Posteriormente serão apresentados os procedimentos metodológicos; os resultados do estudo e as considerações finais.

\section{REVISÃO TEÓRICA}

\section{Redes Inter organizacionais: Conceitos e sua Abrangência entre Instituições de Ensino Superior}

A dinâmica do mercado atual e as transformações ocorridas na gestão das organizações contemporâneas a partir do desenvolvimento de tecnologias, alta competitividade, constantes inovações em processos, produtos e serviços e devido ao fluxo intenso de novas informações, faz com que as organizações busquem 'caminhos' que as ajudarão a desenvolver mecanismos para se manterem atuantes no mercado. Uma das estratégias encontradas foi desenvolver um meio de interação/associação entre organizações, sejam do mesmo ramo de atividade ou não (integração horizontal e vertical, respectivamente). Essa interação pode ser descrita como o processo pelo qual as organizações se relacionam formando uma rede, a qual objetiva primordialmente a criação de novos conhecimentos e benefícios diversos para ambas as partes (BALESTRIN et al., 2005).

As organizações quando formam uma rede estão mais aptas a aprender, uma vez que estão em constante processo de aquisição de conhecimento, troca e interpretação de dados e informações. Identificam-se, através de estudos, que as redes contribuem para transferência de experiências, informações diversas e de conhecimento, sendo capazes de dinamizar os pontos fortes e minimizar os pontos fracos de uma organização ao comparar as atitudes e atividades exercidas com outras organizações (BALESTRIN et al., 2005; CAPALDO, 2007).

A formação de redes cria condições para que seus integrantes assumam um caráter dinâmico para resolução de problemas, pois a cooperação, concorrência, alianças estratégicas, criação de valor e inovações, geração de vantagem competitiva, troca de informações e conhecimento, tecnologia, dentre outros, são atributos que regem a dinâmica das redes interorganizacionais (BRITTO, 2002; MA, 2004; LACOSTE, 2012). Neste sentido, as redes tendem a privilegiar relacionamentos estáveis entre organizações, como forma de impulsionar o aumento da eficiência operacional e aprendizado coletivo (BRITTO, 2002). A complementaridade de competências, valores, práticas, processos, culturas, conhecimento, dentre outros, ao serem compartilhados, geram um ambiente favorável para criação de novos conhecimentos (BALESTRIN et al., 2005).

Ahuja et al. (2012) demonstram que a partir da formação de uma rede, há o desenvolvimento de um mecanismo gerador e condutor de benefícios, seja econômico, social ou tecnológico que se configuram como valores significativos para transferência de conhecimentos diversos e de vantagem competitiva para as organizações. No mesmo sentido, Balestrin, Vargas e Fayard (2005) discutem a formação de rede como forma eficaz, por meio de inter-relações entre 
as empresas, de obter competitividade no mercado, além de ganhos de eficiência e aumento da aprendizagem organizacional (CHEN \& GRADDY, 2010).

As redes Inter organizacionais assumem conceitos responsáveis por ligar diversos atores através de um conjunto de laços (nós), podendo ser os atores: pessoas, equipes ou organizações (BORGATTI \& FOSTER, 2003; CHAUVET et al., 2011). Dessa forma, usar técnicas de análise para avaliar o padrão dos relacionamentos se mostra eficiente para organizações medirem as variáveis que refletem a estrutura global das relações com outros agentes (NOHRIA, 1992). Granovetter (1973) advoga que as redes sociais são fundamentais para a interação em ambientes micro e macro, sendo que os elementos essenciais na ligação são as relações interpessoais formadas por laços fortes ou fracos. Os laços fortes são aqueles formados no longo prazo e ocorrem quando existe certo grau de intensidade e intimidade nas relações de troca. Já os laços fracos são formados por atores que não fazem parte do mesmo círculo social, sendo estes responsáveis por criar 'pontes'/'caminhos' mais curtos com outros grupos, gerando, na maioria das vezes, novas informações, ideias e amizades que podem proporcionar grandes oportunidades de negócios (GRANOVETTER, 1973; BURT, 1992; EKLINDER-FRICK et al., 2012).

Nota-se, portanto, que a eficiência das redes depende de esforços organizacionais na identificação, persuasão e sinergia de indivíduos em prol de esforços coletivos comuns, em que as decisões de cooperação são modeladas com intuito de se evitar potenciais conflitos, facilitar a transmissão dos conhecimentos tácitos entre os membros e, aperfeiçoar a coordenação de esforços (NOHRIA, 1992; BORGATTI \& FOSTER, 2003). Ressalta-se que os maiores ganhos e benefícios em termos de geração de conhecimento e inovação são dinamizados quando a rede é composta por empresas semelhantes (redes horizontais), pois o comprometimento coletivo (cooperação) para criação de um planejamento estratégico único constitui uma oportunidade para a criação de um conhecimento mais robusto (BALESTRIN et al. 2005).

A importância de se formar uma rede, em específico entre Instituições de Ensino Superior, está baseada no processo e oportunidade de cooperação entre as partes, pois se espera alcançar resultados positivos com a parceria realizada, a partir do interesse em se trabalhar em conjunto e atingir objetivos comuns (SEGATTO-MENDES \& SBRAGIA, 2002). Assim, a projeção de parcerias, sob a forma de convênios e consórcios, vem sendo um dos grandes estimuladores da expansão da EaD no país. Dentre as principais iniciativas, destacam-se: O Centro de Educação Superior do Estado do Rio de Janeiro (CEDERJ), criado em 1999; O Instituto Universidade Virtual Brasileira, autorizado em 2003, formado por 6 importantes instituições particulares do país, sendo considerada a maior instituição de ensino superior particular credenciada pelo MEC para ofertar cursos de graduação na modalidade a distância; A Universidade Aberta do Brasil (UAB), instituída em 2005, sendo uma articulação entre IPES, governos estaduais e municipais, responsável por fomentar ações necessárias ao funcionamento da modalidade de educação a distância, principal foco desse estudo; A Universidade Virtual do Estado de São Paulo (UNIVESP), fundada em 2008 a qual abrange um consórcio entre três universidades, coordenadas pela Secretaria de Ensino 
Superior do Estado de São Paulo; O Mestrado Profissional em Matemática em rede nacional (PROFMAT), estabelecido em 2010, constituindo-se como um curso semipresencial, sediado por uma rede de Instituições de Ensino Superior com oferta de cursos em nível nacional.

No contexto internacional, destacam-se: a criação da The Open University (Inglaterra) na década de 1970, a qual ministra cursos a distância para um número expressivo de alunos, sendo um modelo para instituições de diversos países que pretendem utilizar a Educação a Distância; a Universidad Nacional de Educación a Distancia (Espanha) em 1972; a Fundação da Universidade Nacional Aberta (Venezuela) em 1977; Universidade Aberta (Holanda) em 1984; Universidade Nacional Aberta Indira Gandhi (Índia) em 1985 e a Fundação da Universidade Aberta (Portugal) em 1988 (MATIAS-PEREIRA, 2008; MOORE \& KEARSLEY, 2011). Importante a ser destacado, é que o processo de interação e o relacionamento existente entre as IES membros de uma rede são fundamentais para criação de conhecimento e inovação, ao passo que essas mesmas Instituições (atores), agindo sozinhas, não desenvolveriam capacidades quando em conjunto.

\section{Educação a Distância e o Sistema UAB}

Devido à limitação de tempo, à dinamicidade do fluxo de informação, e à incessante necessidade de aprimoramento das habilidades humanas e do conhecimento profissional, a EaD desde a década de 1960 vem crescendo substancialmente tanto nos países desenvolvidos quanto naqueles em fase de desenvolvimento, como alternativa para disseminar e nivelar o potencial educacional de uma população (PRETI, 2000). Santos (2012) assevera que a partir da inserção dos indivíduos no meio educacional há uma maior interação e dinamicidade nas relações sociais, assim como nos aspectos relacionados às atividades laborais.

Um dos objetivos da Educação a Distância é minimizar e superar barreiras, reduzindo fronteiras que impedem o acesso à informação e ao conhecimento. Dessa forma, o espaço geográfico não é mais um agravante que impossibilita o aprendizado contínuo dos alunos. A EaD tem a finalidade de proporcionar o encurtamento de distâncias e a possibilidade de um gerenciamento mais eficiente do tempo por parte daqueles que optam por essa modalidade de educação. A busca por essa modalidade de educação remete-nos acreditar que cada vez mais as pessoas têm se deparado com a necessidade de aprimoramento e especialização de sua força de trabalho (NUNES, 2009; HUH et al., 2010). Há de se destacar que a EaD é em grande parte assumida por alunos mais adultos que já estão inseridos no mercado de trabalho em detrimento dos alunos dos cursos presenciais (NUNES 2009; MOORE \& KEARSLEY, 2011).

Fato relevante também a ser discutido é a diferença de comportamento entre estudantes de curso presencial e curso a distância. Exige-se do aluno de curso a distância muito mais disciplina, interesse e responsabilidade para realização de atividades individuais, proficiência para leitura e escrita, motivação, entre outros, rompendo barreiras que dinamizem a criação de seu próprio espaço de aprendizado e conhecimento (BELCHEIR \& CUCEK, 2002; KERR et al., 2006). 
Parietti e Turi (2011) relatam em seu estudo que tanto professores quanto alunos avaliam a Educação a Distância positivamente, pois a mesma proporciona flexibilidade e gerenciamento do tempo e do local de estudo. Da mesma forma, Mohamed et al. (2011) relevam que a EaD é capaz de proporcionar benefícios sociais, econômicos e menos dispêndio de tempo em relação à educação tradicional, especialmente por não haver a necessidade de constantes deslocamentos físicos até o local de uma sala de aula presencial. Pesquisas realizadas por Watters e Robertson (2009); Allen e Seaman (2010) e Liu (2012) demonstraram que a percepção dos alunos sobre a qualidade da Educação a Distância é compatível com a qualidade da educação presencial, ao contrário do que muitas pessoas acreditam.

Corroborando esses conceitos, Huh et al. (2010) e Driscoll et al. (2012), ao pesquisarem alunos matriculados em cursos nas modalidades presencial e a distância, identificaram não haver diferenças significativas no desempenho dos estudantes. Assim, a qualidade do ensino/aprendizado, medido pelas notas obtidas nos testes das disciplinas, foi o mesmo nas duas modalidades. Tais estudos podem ser confirmados no Brasil pelas notas do exame nacional de desempenho de estudante (ENADE) em que, quando possível a comparação entre cursos, alunos de cursos a distância tiveram desempenho melhor que dos alunos de educação presencial (INEP/ENADE, 2013).

Contudo, observa-se que a interação, formação e a capacidade didática online dos docentes que ministram nesta modalidade de educação são cruciais para a satisfação, aprendizagem e qualidade do conhecimento repassado aos discentes (ARBAUGH et al., 2006; REDPATH, 2012). Ademais, cabe ressaltar que a expansão da EaD somente foi possível a partir da utilização intensa das TIC's, as quais deram suporte suficiente para dinamização do contato assíncrono e da redução do espaço geográfico presentes na modalidade EaD (FINCH \& JACOBS, 2012; RIENTIES et al., 2013). A partir da disponibilidade dos recursos tecnológicos, de pessoas que demandam aprimoramento e qualificação profissional, do exigente mercado laboral; da necessidade de melhoria da oferta de cursos superiores; dentre outros fatores, é que foram instituídas algumas redes envolvendo Instituições Públicas de Ensino Superior (IPES) como o Sistema Universidade Aberta do Brasil (UAB), o qual tem sido responsável pela dinamização da EaD.

Este foi instituído em 2005 através de uma parceria do MEC (Ministério da Educação) com a ANDIFES (Associação Nacional dos Dirigentes das Instituições de Ensino Superior) e empresas estatais, com foco nas políticas e na gestão da educação superior. Além disso, a UAB é uma política pública articulada entre a Secretaria de Educação a Distância (SEED/MEC) e a Diretoria de Educação a Distância (DED/CAPES), buscando desenvolver a modalidade de educação a distância para expandir a educação superior no país frente às exigências do mercado de trabalho ( MOTA, 2009; UAB/CAPES, 2013). Corroborando, Alves (2009, p.12) advoga que o Sistema UAB 'não é uma universidade propriamente dita, mas sim um consórcio de instituições públicas de ensino superior' que visa expandir, interiorizar e democratizar a educação superior pública gratuita 
e de qualidade no país para camadas da população que têm dificuldade de acesso à formação tradicional (presencial).

A partir da abertura de edital público, denominado UAB1, para viabilizar a oferta de curso de Administração a distância, foi instituído o curso de bacharelado em Administração a distância (piloto), sendo o primeiro curso oferecido pelo sistema UAB em âmbito nacional ofertado por 22 IPES nas cinco regiões do país. Este foi uma articulação entre a SEED-MEC, Instituições de Ensino Superior Federais e Estaduais e Banco do Brasil, sendo este, o principal financiador e cliente do projeto (GIEBELEN, 2011; NOVAIS \& FERNANDES, 2011). Por ter sido o primeiro curso com tal envergadura, o curso (piloto) se tornou orientador e um exemplo para a instituição de novos cursos, mostrando-se então fundamental ao processo de institucionalização de distintos cursos na modalidade a distância (ALVES, 2012), fato que justifica a escolha desse curso no respectivo estudo.

Para esboçar a abrangência dos cursos ministrados na modalidade a distância sob a égide do Sistema da Universidade Aberta do Brasil a partir do curso (piloto), atualmente encontram-se credenciadas 96 instituições públicas de ensino (federais e estaduais) que ministram um total de 1.248 cursos apoiados por 668 polos presencial espalhados pelas diversas regiões do Brasil UAB/CAPES (2013). Como meio de viabilizar esse estudo, na próxima seção serão descritos os procedimentos metodológicos utilizados para se coletar os dados e atingir os objetivos propostos.

\section{METODOLOGIA}

O estudo se caracteriza como sendo qualitativo e descritivo-exploratório (VERGARA, 2006), partindo-se de entrevistas com coordenadores do curso (piloto) de IPES distintas participantes do sistema UAB. O objetivo é identificar, sob a ótica dos coordenadores, como se deu a interação/relacionamento entre as universidades e qual a repercussão dessa rede para a dinamização da EAD, além de identificar algumas dificuldades enfrentadas por eles e os possíveis benefícios que foram obtidos pelos egressos do curso. Ressalta-se que a estratégia qualitativa engloba diversas técnicas com a finalidade de explorar, descrever e codificar a simbologia de um emaranhado de dados significantes para a pesquisa (BANDEIRA-DE-MELO; CUNHA, 2003). Ademais, o estudo se caracteriza como exploratório devido à intensão de se pesquisar algo ainda incipiente na literatura.

Como estratégia de coleta de dados, fez-se contato via e-mail com todos os 22 coordenadores do respectivo curso para explicar os objetivos da pesquisa e convidá-los a participar do estudo via entrevistas. Os e-mails foram obtidos por meio do site da UAB/CAPES (2013) e de contatos pessoais. Aceitaram participar e concederam entrevistas 6 coordenadores. Vale ressaltar que os nomes deles e de suas respectivas instituições foram tratados em absoluto sigilo, divulgando-se apenas resultados consolidados, sem identificação individual. Os coordenadores foram então identificados como C01, C02, C03, C04, C05 e C06, de acordo com a 
ordem das entrevistas realizadas.

As entrevistas baseadas em um roteiro com 10 perguntas semiestruturadas foram realizadas via online com 4 coordenadores e face-to-face com 2 coordenadores entre os meses de novembro a dezembro de 2013. Assim, a escolha dos coordenadores entrevistados deu-se por uma amostragem não probabilística por conveniência. Neste tipo de amostragem os indivíduos foram escolhidos simplesmente por serem mais acessíveis ou então por serem mais fáceis de serem avaliados (ALENCAR, 2000; BRUNI, 2010). Por fim, o tratamento e a interpretação das entrevistas foram realizados por meio da análise de conteúdo proposta por Bardin (2007), buscando atingir maior descrição no conteúdo das mensagens repassadas pelos entrevistados. Essa técnica teve o objetivo de enriquecer o conteúdo das mensagens capturadas dos pesquisados, investigando e concluindo com maior exatidão os objetivos desse estudo.

\section{RESULTADOS}

Quando solicitados a relatar como surgiu a possibilidade de oferecer o curso (piloto), a maioria dos coordenadores ficou sabendo do edital por meio de terceiros. O coordenador 01 (C01) relatou que sua instituição ficou sabendo do edital do curso através do prefeito de uma pequena cidade que tinha a intenção que sua cidade fosse palco de um polo presencial. C02 informou que uma professora da mesma IPES, mas de outro departamento, em viagem à Brasília trouxe a informação do curso, o que muito interessou ao departamento de Administração. Já os entrevistados $\mathrm{C05}$ e $\mathrm{C06}$ foram convidados pelo Banco do Brasil e por carta enviada pela Universidade do Estado da Bahia (UNEB), respectivamente.

A partir destas informações, identifica-se que o curso (piloto) não teve um programa de divulgação eficaz, visto que cada IPES recebeu a informação sobre o mesmo de fontes variadas. Muitas IPES nem mesmo ficaram sabendo da oferta do curso, o que pode ter impedido que outras também ofertassem o curso em pauta. Assim, demonstra-se que um fluxo de informação eficiente poderia ter garantido maior número de IPES participantes, caso as mesmas tivessem conhecimento prévio do curso (piloto).

Sobre quais foram às primeiras impressões dos coordenadores em relação ao curso, a maioria dos entrevistados disseram que havia certo receio por ser uma modalidade de ensino nova e consequentemente por falta de experiência e conhecimento nessa área. Contudo, os coordenadores se mostraram com muita determinação para ministrarem o curso, visto este ter sido considerado como uma ótima oportunidade para disseminação da EaD. O coordenador C01 relatou que: "era uma oportunidade de aprender". Somente o coordenador C04 informou que já tinha conhecimento em EaD, mas foi enfático ao dizer que o curso proporcionou grande experiência para sua vida acadêmica. Assim, percebe-se que apesar do desafio e 'medo' do novo, os coordenadores viram no curso (piloto) uma grande oportunidade para desenvolverem a EaD e disseminar conhecimentos entre os participantes, além de ser um 'grande projeto a realizar de alto 
valor social' conforme relatou C03.

Quando abordados sobre suas expectativas iniciais com o curso, todos disseram que o curso proporcionaria grande aprendizado, pois eles não tinham experiência anterior com EaD e, apesar de ser um curso de bacharelado em Administração, a modalidade era totalmente diferente da modalidade presencial. Dessa forma teriam que aprender e trocar experiências para conseguirem ministrar o curso, o que proporcionaria inserção de novos conhecimentos e benefícios diversos para ambas as partes (BALESTRI et al., 2005). Assim facilitaria a transferência dos conhecimentos obtidos entre os membros, aperfeiçoando a coordenação de esforços e gerando maiores ganhos para todos (NOHRIA, 1992; BORGATTI \& FOSTER, 2003). Já C02 relatou: "Que o curso foi um grande processo de aprendizado que não envolveu somente alunos, mas também todo o corpo social do curso. Aprendemos muito com o curso piloto, O piloto foi o protótipo da UAB".

Nos relatos realizados aqui, comprova-se a afirmação de Alves (2012), a qual ressaltou que vários outros cursos surgiram após o curso (piloto), pois este foi fundamental para dar apoio ao processo de institucionalização de distintos cursos na modalidade a distância. Sobre as principais dificuldades enfrentadas pela coordenação do curso, várias dificuldades foram apontadas pelos coordenadores, os quais mostraram que tiveram que acreditar no modelo e procurarem sempre conhecer e buscar informações/soluções para o 'novo' modelo de educação, afirmando-se assim a importância do contato/relacionamento entre as partes para amenizar as incertezas e dificuldades encontradas.

Assim, a falta de experiência para lidar com o tipo de percurso didático pedagógico exigido pela EaD fez com que vários coordenadores recorressem a outros cursos de EaD dentro da própria instituição ou em instituições que já estavam praticando a modalidade de educação em pauta há mais tempo, objetivando apoiar e aprimorar suas tarefas e atividades. A partir de tais relatos, corrobora-se a afirmação que as redes contribuem para transferência de experiências, informações diversas e de conhecimento, sendo capazes de dinamizar os pontos fortes e minimizar os pontos fracos de uma organização ao comparar as atitudes e atividades exercidas com outras organizações (BALESTRIN et al., 2005; CAPALDO, 2007).

Ao serem questionados sobre como se deu a atuação/interação como coordenador em relação às outras IPES, os entrevistados foram unânimes ao abordarem a existência do fórum de coordenadores que se dava por encontros presenciais ocorridos em Brasília duas ou três vezes ao ano. Os fóruns foram exercícios de reflexões, de trocas de práticas pedagógicas, que permitiram grandes painéis de trocas de experiências e aprendizado. C03 relatou:

Nos encontros do fórum dos coordenadores onde apresentávamos e discutíamos nossas experiências e aprendíamos com os erros e acertos uns dos outros - a relação de amizade que surgiu entre os coordenadores, a transparência do fórum, o esforço da presidência do fórum em dar continuidade ao trabalho e nos representar junto a UAB foram fatores determinantes do sucesso do projeto.

O fórum era o momento "para compartilhamento de experiências e planejamento das 
etapas seguintes", relatou C04. Diante de tais perspectivas, identificou-se que grandes desafios foram superados através do compartilhamento de informações, experiências, erros e acertos. Foi relatado também haver um canal estreito de comunicação entre os coordenadores via e-mail, telefone, contato pessoal, entre outros, visando articular a troca de informações, inclusive com o responsável pelo curso no Banco do Brasil, demonstrando-se aqui a importância da troca de informações para sucesso do curso (SEGATTO-MENDES \& SBRAGIA, 2002).

Os coordenadores foram abordados também quanto a sua percepção em relação aos benefícios conseguidos pelos egressos, sendo unânime a percepção do beneficio social alcançado pelos alunos. C04 afirmou: "acredito que tenha sido a realização de um sonho de concluir um curso superior, os conhecimentos adquiridos e o diploma da Universidade Federal". Se não fosse a oportunidade de um curso a distância, muitos alunos nunca teriam conseguido estudar. C03 relatou que os alunos aumentaram a autoestima, a inserção social e ampliação da rede de relacionamento. C02 afirmou que a alegria das pessoas, o contentamento delas, a capacidade que elas tiveram de superar barreiras, dificuldades, limitações, realizações pessoais foram os maiores benefícios conseguidos pelos egressos.

C03 e C06 afirmaram que muitos alunos após terminarem o curso fizeram cursos de especialização, entraram no mestrado e foram aprovados em concurso público, demonstrando que o curso piloto serviu para muitos como 'alicerce' para obtenção de novos títulos e conhecimentos. Quando questionados se as expectativas iniciais em relação ao curso foram atingidas, todos os entrevistados disseram que as expectativas foram atingidas e até 'hipersuperadas', relatou C02. C01 afirmou que "O curso foi além do que agente esperava. pois tínhamos muito receio se a gente ia dar conta". C02 disse que "os alunos sofreram, nós sofremos, mas foi superado. Você não constrói o sucesso sem essa entrega". C03 e C06 relataram que o curso piloto deu margem para a implantação de outros cursos EaD em suas instituições. C03 afirmou que "a instituição hoje tem se mostrado cada vez mais favorável a essa modalidade de ensino e o preconceito local se reduz a passos largos". C04 relatou que o curso não deixou algo a desejar, sendo que "o curso deu origem ao Programa Nacional de Formação em Administração Pública (PNAP) que é um projeto nacional de sucesso na EaD. Deixou saudades de todos que participaram dos Fóruns de Coordenadores". C02 afirmou que: "O projeto piloto literalmente não acabou", pois muitas pessoas e universidades ainda aproveitam da experiência para utilização em outros cursos, como por exemplo, em outros cursos de graduação ou até mesmo de pósgraduação. Segundo $\mathrm{C02}$, "O piloto foi um grande processo de aprendizado para nós". Corroborando esses conceitos, C01 e C04 enfatizaram, respectivamente, que "o curso piloto serviu de aprendizado"; "sendo um grande aprendizado para todos que dele participaram". A partir de tais relatos identifica-se que o curso foi um importante instrumento de expansão da educação superior a distância em muitas IPES, assim como relatado por Alves (2012), visto ter sido, em muitas delas, o primeiro curso de graduação com tal envergadura ministrado a distância. 


\section{CONCLUSÕES}

O presente artigo teve como objetivo primordial identificar, na percepção dos coordenadores do curso de Administração a distância (piloto) pelo Sistema UAB, como se deu a interação/relacionamento entre as universidades e qual a repercussão dessa rede para a dinamização da EAD, assim como identificar algumas dificuldades enfrentadas pelos coordenadores e os possíveis benefícios que foram obtidos pelos egressos do curso.

Constatou-se pelos relatos que o curso (piloto) não teve um programa de divulgação eficaz, visto que cada IPES recebeu a informação sobre o curso de fontes variadas; O curso (piloto) foi um grande desafio para os coordenadores, contudo a partir de muitos esforços e dificuldades o curso teve seu êxito e 'abriu as portas' para novos cursos na modalidade a distância. Isso foi conseguido por meio da interação contínua entre os coordenadores, a partir do estabelecimento dos fóruns que garantiram a troca de informações e experiências diversas, pois buscou-se facilitar a transmissão dos conhecimentos tácitos entre os membros e aperfeiçoar a coordenação de esforços (NOHRIA, 1992; BORGATTI \& FOSTER, 2003).

A partir de encontros presenciais entre os coordenadores foi possível o exercício de reflexões e de novas práticas pedagógicas, que permitiram grandes painéis de trocas de experiências e aprendizado, assim como identificado nos estudos de (BALESTRIN et al., 2005; CAPALDO, 2007). Conclui-se que o relacionamento criado nos fóruns foi fator fundamental para sucesso do curso, pois naqueles momentos eram planejadas ações relativas ao curso que seriam utilizadas por todos, além de ganhos de eficiência e aumento da aprendizagem organizacional (CHEN \& GRADDY, 2010).

Foi relatado também haver um canal estreito de comunicação entre os coordenadores via e-mail, telefone, contato pessoal, entre outros, visando articular a troca de informações, inclusive com o responsável pelo curso no Banco do Brasil, demonstrando-se a importância da rede de relacionamento para o sucesso do curso (SEGATTO-MENDES \& SBRAGIA, 2002). Ademais, o comprometimento coletivo (cooperação) para criação de um planejamento estratégico constituiu uma oportunidade para a criação de um conhecimento mais robusto (BALESTRIN et al., 2005).

No que tange os resultados gerais, identifica-se que o curso piloto foi um importante instrumento de expansão da educação superior pública em muitas IPES, o qual foi capaz de proporcionar educação superior para pessoas que há muito haviam deixado os bancos escolares e não possuíam recursos (financeiros, de tempo, de mobilidade, dentre outros) para aderirem aos cursos superiores do modelo de educação tradicional (presencial). Além do mais, o curso foi fundamental na capacitação de seus egressos, pois proporcionou mão de obra mais qualificada para os ditames do mercado contemporâneo, ao passo que foi um instrumento eficiente da política pública brasileira de educação ao conseguir proporcionar educação superior para pessoas que não teriam condições nos moldes tradicionais. Santos (2012) assevera que a partir da inserção dos indivíduos no meio educacional há uma maior interação e dinamicidade nas relações sociais, 
assim como nos aspectos relacionados às atividades laborais, algo conseguido pelo curso (piloto) (pelo menos sob a ótica dos coordenadores pesquisados).

Ademais os resultados positivos obtidos por meio da rede formada entre as universidades podem ser reconhecidos por seu caráter tangível, como aumento do número de cursos acadêmicos disponíveis para a sociedade, ou intangível, como aprendizado, criação e disseminação de conhecimento, inovação, dentre outros. O curso (piloto) demonstrou, portanto, que por meio da inter-relação entre as IPES e a partir das trocas intensas de experiências, foi possível garantir sucesso das ações implantadas. Entretanto, algumas limitações no estudo devem ser consideradas. Devido somente 6 coordenadores terem participados do estudo, caracterizando-se como uma amostra não probabilística por conveniência, não se pode generalizar os resultados para todos os atores (IPES, coordenadores e egressos) que participaram do curso (piloto); A ocorrência de subjetividade dos autores, visto que a análise de conteúdo (BARDIN, 2007) poderia ter sido interpretada de forma diferente caso fosse realizada por outro pesquisador.

Para novas pesquisas, julga-se procedente analisar em outros cursos ministrados na modalidade a distância, como por exemplo, no Programa Nacional de Formação em Administração Pública (PNAP), como tem se dado a interação e o relacionamento entre as IPES e quais as repercussões geradas a partir desses relacionamentos para oferta de cursos a distância. Outro ponto a ser explorado é a delimitação de um 'modelo de rede' entre as IES, objetivando a uniformidade de práticas e atividades que dinamizem a potencialização dos cursos superiores à distância.

\section{REFERÊNCIAS}

AHUJA, G.; SODA, G.; ZAHEER, A..The genesis and dynamics of Organzational Networks. Organization Science. v.23, n.2, p.434-448, 2012.

ALENCAR, E.. Introdução à metodologia de pesquisa. Lavras: UFLA, 2000.

ALLEN, I. E.; SEAMAN, J.. Class differences: On-line education in the United States. Needham: Sloan Consortium, 2010.

ALVES, J. R. M.. A história da EAD no Brasil. São Paulo: Pearson Education do Brasil, 2009.

ALVES, R. R.. A Institucionalização dos cursos de Administração Pública a Distância das Universidades Públicas: os casos UFLA e UFU. Dissertação (Mestrado em Administração) - Universidade Federal de Lavras, Lavras, 2012.

ARBAUGH, J. B; BENBUNAN-FICH, R.. An Investigation of epistemological and social dimensions of teaching in online learning environments. Academy of Management Learning \& Education, v.5, n.4, p. 435-447, 2006.

BALESTRIN, A.; VARGAS, L. M.; FAYARD, P.. Ampliação interorganizacional do conhecimento: o caso das redes de cooperação. Revista Eletrônica de Administração, Porto Alegre, v.11, n.1, p.1-25, 2005.

BANDEIRA-DE-MELO, R.; CUNHA, C. J. C. A.. A operacionalizando o Método da GroundedTheory nas Pesquisas em Estratégia: Técnicas e Procedimentos de Análise do Software Atlas/TI. In: ENCONTRO ANUAL DA ASSOCIAÇÃO DOS PROGRAMAS DE PÓS-GRADUAÇÃO EM ADMINISTRAÇÃO. 27. Anais. Rio de Janeiro: ANPAD, 2003. 
BARDIN, L.. Análise de conteúdo. Lisboa: ed. 70, 2007.

BELCHEIR, M. J.; CUCEK, M.. Faculty Perceptions of Teaching Distance Education Courses. Idaho: Report Research, 2002.

BORGATTI, S. P.; FOSTER, P.. The network paradigm in organizational research: a review and typology. Journal of Management, n. 29, v.6, p.991-1013, 2003.

BRITTO, J.. Cooperação interindustrial e redes de empresas. 2 ed. São Paulo: Atlas, 2010.

BURT, R. S.. The social structure of competition. Boston: Harvard Business School Press, 1992.

CAPALDO, A.. Network structure and innovation: the leverage of a dual network as a distinctive relational capability. Strategic Management Journal, v.28, p.585-608, 2007.

CHAUVET, V.; CHOLLET, B.; SODA, G.; HUAULT, I.. The contribution of network research to managerial culture and practice. European Management Journal, v.29, p.321- 334, 2011.

CHEN, B.; GRADDY, E. A.. The Effectiveness of Nonprofit Lead-Organization Networks for Social Service Delivery. Nonprofit Management \& Leadership, v.20, n.4, 2010.

DRISCOLL, A.; JICHA, K.; A. N.; TICHAVSKY, L.; THOMPSON, G.. An Online Courses Deliver In-class Results? A Comparison of Student Performance and Satisfaction in an Online versus a Face-to-face Introductory Sociology Course. Teaching Sociology, v.40, n.4, 2012.

EKLINDER-FRICK, J.; ERIKSSON, L. T. HALLÉN, L.. Effects of social capital on processes in a regional strategic network. Industrial Marketing Management, v.41, 2012.

ESTIVALETE, V. F. B.; GOMES, T. C.; CAMPOS, S. A. P.; RIBAS, F. L.; SOUZA, G.. Motivos, benefícios e aprendizagem: um estudo envolvendo relacionamentos interorganizacionais no terceiro setor. Revista Brasileira de Administração Científica, v.3, n.3, p.201-215, 2012.

FALK, C. F.; BLAYLOCK, B. K.. Strategically planning campuses for the "newer students" in higher education. Academy of Educational Leadership Journal, v.14, n. 3, 2010.

FINCH, D.; JACOBS, K.. Online Education: Best Practices to Promote Learning. Proceedings of the Human Factors and Ergonomics Society Annual Meeting, 2012.

GIEBELEN, J. B. M. E.. Arquiteturas cognitivas construídas no curso de Administração a Distânciaprojeto UAB/Banco do Brasil. Dissertação (Mestrado em Educação) - Universidade Federal da Paraiba, João Pessoa, 2011.

GRANOVETTER, M. S.. The strength of weak ties. American Journal of Sociology, v.6, p.1360-1380, 1973.

HUH, S.; JONGDAE, J.; LEE, K. J.; YOO, S.. Differential effects of student characteristics on performance: online vis-a-vis offline accounting courses. Academy of Educational Leadership Journal, v.14, n.4, 2010.

INEP/ENADE.Portal.

KERR, M. S.; RYNEARSON, K.; KERR, M. C.. Student characteristics for online learning success. Internet and Higher Education, v.9, p.91-105, 2006.

LACOSTE, S.. "Vertical coopetition": the key account perspective. Industrial Marketing Management, v. 41, p.649-658, 2012.

MA, H.. Toward global competitive advantage: creation, competition, cooperation, and co-option. Management Decision, v.42, n.7, p.907-924, 2004.

MATIAS-PEREIRA, J.. Políticas públicas de educação no Brasil: a utilização da EAD como instrumento de inclusão social. Journal of Technology Management \& Innovation, v.2, p.44-55, 2008.

MOHAMED, F. A.; HASSAN, A. M.; SPENCER, B.. Conceptualization and measurement of perceived risk of 
online education. Academy of Educational Leadership Journal, v.15, n.4, 2011.

MOORE, M. G.; KEARSLEY, G.. Educacao a distância: Uma visão Integrada. São Paulo: Cengage Learning, 2011.

MOTA, R.. A Universidade Aberta do Brasil. São Paulo: Pearson Education do Brasil, 2009.

NOHRIA, N.. Is a network perspective a useful way of studying organizations? Boston: Harvard Business School Press, 1992.

NOVAIS, S. M.; FERNANDES, A. S. S.. A Institucionalização do Ensino a Distância no Brasil: o caso da Graduação em Administração na Universidade Federal do rio Grande do Norte (UFRN). Revista de Ciência da Administração, Florianópolis, v.13, n.28, p.173-201, 2011.

NUNES, L. N.; KLUCK, M. M.; FACHEL, J. M. G.. Uso da implantação múltipla de dados faltantes: uma simulação utilizando dados epidemiológicos. Rio de Janeiro: Cad. Saúde pública, 2009.

PARIETTI, I. S. C.; TURI, D. M.. Assessment of the online instructor. Academy of Educational Leadership Journal, v.15, 2011.

PRETI, O. (org.) Educação a Distância: construindo significados. Brasília: Plano, 2000.

REDPATH, L.. Confronting the Bias Against On-Line Learning in Management Education. Academy of Management Learning \& Education, v.11, n.1, p.125-140, 2012.

RIENTIES, B.; BROUWER, N.; LYGO-BAKER, S.. The effects of online professional development on higher education teachers' beliefs and intentions towards learning facilitation and technology. Teaching and Teacher Education, v.29, p.122 -131, 2013.

SANTOS, M.. Educação e sua relação com o trabalho: limites e possibilidades da Teoria do Capital Humano face ao desenvolvimento de potencialidades humanas. Revista FACED, v.1, n.18, 2012.

SEGATTO-MENDES, A. P.; SBRAGIA, R.. O processo de cooperação universidade-empresa em universidades brasileiras. Revista de Administração, v.37, n.4, p.58-71,. 2002.

VERGARA, S. S.. Métodos de Pesquisa em Administração. São Paulo: Atlas, 2006.

WATTERS, M. P.; ROBERTSON, P. J.. Online delivery of accounting courses: student perceptions. Academy of Educational Leadership Journal, v.13, n.3, 2009. 